\title{
ENHANCEMENT OF LORNOXICAM SOLUBILITY BY INCLUSION COMPLEXATION WITH CYCLODEXTRIN: PREPARATION AND CHARACTERIZATION
}

\author{
SHAHIRA F. EL-MENSHAWE ${ }^{1}$, ESSAM EISSA*1, ADEL A. ALI' ${ }^{1}$, AHMED A. ABDERHMAN²
}

1Pharmaceutics and Industrial Pharmacy Department, Faculty of Pharmacy, Beni-Suef University, Beni-Suef, Egypt, ${ }^{2}$ Pharmaceutics and Industrial Pharmacy Department, Faculty of Pharmacy, Cairo University, Cairo, Egypt

Email: dressamceutics@yahoo.com

Received: 23 Aug 2016 Revised and Accepted: 11 Nov 2016

\begin{abstract}
Objective: Lornoxicam is a potent anti-inflammatory drug which has analgesic and antipyretic properties. It is water-insoluble powder. The inclusion complexes of lornoxicam (LOR) with $\beta$-cyclodextrin ( $\beta C D$ ) and 2-hydroxypropyl- $\beta$-cyclodextrin (HPCD) were prepared and characterised in order to improve the solubility of the drug and enhance its bioavailability.

Methods: Complexes were prepared by physical mixing and freeze-drying in three different drug/polymer ratios (1:1, 1:2 and 3:2). The solid complexes were characterised through differential scanning calorimetry (DSC), scanning electron microscopy (SEM), X-ray diffraction, nuclear magnetic resonance (NMR) spectroscopy, and Fourier transformed infrared (FTIR) spectroscopy.
\end{abstract}

Results: The data showed that LOR may be complexed with cyclodextrin (CD) forming soluble complexes. The lyophilized 1:2 LOR/HPCD complex is the most soluble.

Conclusion: Solubility increases with lyophilization than with physical mixing and by the use of HPCD than $\beta C D$ in complexation.

Keywords: Lornoxicam, Cyclodextrin, Lyophilization, Physical mixing, Inclusion complex

(C) 2017 The Authors. Published by Innovare Academic Sciences Pvt Ltd. This is an open access article under the CC BY license (http://creativecommons.org/licenses/by/4. 0/) DOI: http://dx.doi.org/10.22159/ijpps.2017v9i1.14848

\section{INTRODUCTION}

Lornoxicam (chlo-rtenoxicam) is a non-steroidal anti-inflammatory drug (NSAID) of the oxicam class with analgesic, antiinflammatory and antipyretic properties. It is available in oral and parenteral formulations. LOR is used for the treatment of various types of pain, especially those resulting from inflammatory diseases of the joints, osteoarthritis, and rheumatoid arthritis [1]. The physicochemical characteristics of these molecules vary greatly depending upon the environment [2]. LOR is a yellow insoluble powder. Supra-molecules are ordered molecular aggregates associated with two or more molecules, ions or coordination compounds through intermolecular interaction, which has particular functions. Examples of host molecules in supra-molecular chemistry include crown ethers, crypates, calixarenes, and cyclodextrins. CDs are cyclic oligosaccharides with several d-glucopyranoses linked by $\alpha-1,4$-glycosidic bonds [3]. $\alpha$-, $\beta$-and $\gamma$-CD are the most common CDs, which have six, seven and eight glucose units, respectively [4]. Due to lack of free rotation of the bonds connecting the glucopyranose units, the CDs have a toroid or cone shape, where the primary hydroxyl groups are located on the narrow side of the torus while the secondary hydroxyl groups are located on the wider edge. This arrangement provides the formation of an internal hydrophobic cavity and a hydrophilic external surface. The lipophilic cavity provides a microenvironment into which appropriately sized nonpolar moieties can enter to form inclusion complex [5]. CDs are capable of forming inclusion complexes with many drugs by taking up a whole drug molecule, or a part of it, into the cavity of the CD molecule. Drug CDs complexes can improve the clinical usage of drugs by increasing their aqueous solubility, dissolution rate, and pharmaceutical availability [6,7]. CDs can also act as penetration enhancers by increasing drug availability at the surface of the biological barrier $[8,9]$. CDs are able to improve the solubility of a lot of drugs, such as phenytoin [10], acyclovir [11], glyburide [12], celecoxib [13], bromazepam [14] and resveratrol [15]. In our study, we evaluated the complexation of LOR with $\beta C D$ and HPCD prepared by two different methods in different molar ratios and were then in vitro characterised to investigate more soluble LOR complexes with higher bioavailability.

\section{MATERIALS AND METHODS}

Chemicals

LOR as a gift from EPCI (pharmaceutical company), $\beta C D$ and HPCD were purchased from SIGMA-ALDRICH. All chemicals are of analytical grade.

Methods

Preparation of LOR inclusion complexes

LOR complexes with $\beta C D$ and HPCD in three different molar ratios were prepared using two different techniques (table 1);

- Physical mixing: physical mixtures were prepared by homogeneous blending of previously weighed LOR and CD in a mortar for $30 \mathrm{~min}$

- Freeze-drying: freeze-dried products were prepared by dissolving the different molar ratios (mentioned above) in suitable volumes of $50 \%$ methanol in water. The solutions were shaken for $24 \mathrm{~h}$ at $25{ }^{\circ} \mathrm{C}$, frozen at-20 ${ }^{\circ} \mathrm{C}$ and lyophilized in a freeze dryer (Edwards EF4 Modulyo freeze dryer, UK) for $48 \mathrm{~h}$.

Characterization of the prepared inclusion complexes

Solubility study

A solubility study [7] was carried out by adding excess amounts of prepared mixtures to a suitable volume of aqueous media and stirred for $24 \mathrm{~h}$ at $25^{\circ} \mathrm{C}$. The dispersion was then filtered through $0.45 \mu$ disc filter and the solutions were assayed spectrophotometrically using UV spectrophotometer (Spectro 22 Digital labo Med, USA) at $381 \mathrm{~nm}$ for determination of the amount of LOR dissolved. Each molar ratio was done in triplicate.

Differential scanning calorimetry (DSC)

DSC thermograms were obtained with a Shimadzu DSC-60 calorimeter (Shimadzu Co., Kyoto, Japan) under a dynamic nitrogen atmosphere at a heating rate of $10{ }^{\circ} \mathrm{C}$. Min-1. Samples were accurately weighted and submitted to heat scanning from $25{ }^{\circ} \mathrm{C}$ to 
$350{ }^{\circ} \mathrm{C}$ in a sealed aluminum pan. An empty sealed aluminum pan was used as a reference.

\section{Scanning electron microscopy (SEM)}

The morphology of the inclusion complexes was investigated using SEM (Jeol JSM 6510 microscope, Japan) at a voltage of $20 \mathrm{kV}$. The samples were previously mounted on aluminum stubs using doublesided adhesive tape and vacuum-coated with a thin layer of gold.

\section{X-ray diffraction}

X-ray diffraction patterns were obtained on Empyrean diffract meter (PANalyticalB. V, Netherlands) with $\mathrm{Cu} \mathrm{K} \alpha$ radiation, the voltage of $40 \mathrm{kV}$ and current of $30 \mathrm{~mA}$ with a scan time of 0.5 seconds.

\section{Nuclear magnetic resonance spectroscopy}

NMR spectra were recorded to investigate the chemical structure of the complexes using (Bruker DRX400-AVANCE) spectrometer operating at $400 \mathrm{MHz}$, equipped with a $5 \mathrm{~mm}$ inverse probe with the z-gradient coil. DMSO-d6 (isotopic purity at least 99.5\%) was used as a solvent and tetramethylsilane (TMS) as an internal standard. One-dimensional $1 \mathrm{H}$ NMR spectra were acquired under standard conditions. All experiments were recorded at $300 \mathrm{~K}$.

\section{Fourier transform infrared (FT-IR)}

FT-IR spectra were recorded on a Perkin-Elmer Model 1600 apparatus using $\mathrm{KBr}$ discs, samples corresponding to $2.0 \mathrm{mg}$ of LOR/CD mixtures were compressed and tested in the range of 4000-400 $\mathrm{cm}^{-1}$.

\section{Statistical analysis}

All measurements in the study were carried out in triplicate and the reported data were expressed as the mean values \pm standard deviation. One-way analysis of variance followed by the TurkeyKramer multiple comparisons test using GraphPad prism software v.5 was used to determine the statistical significance of the differences in solubility and crystallinity. All P-values were twotailed, and differences were considered significant when the P-value was less than 0.05 [16]. Statistical analysis of the data obtained was performed with computer software [17].

\section{RESULTS AND DISCUSSION}

In cyclodextrin chemistry, inclusion complexation is accomplished by the intermolecular interaction between CD and guest molecule, which leads to the penetration of guest molecule partially or completely into the cavity of the CD. Contrarily, if some guest molecules only reside in the packing interstice of $C D$, an encapsulation interaction occurs [18]. Complexation between CD and organic compounds with low polarity was studied for decades $[19,20]$. Past research indicated that the process of inclusion complexation between CD and guest is driven by electrostatic forces, van der Waals forces, hydrophobic interactions, hydrogen bonding and release of conformational strain [21, 22]. The driving forces always coexist or have a synergistic effect. The relative strength of each force is usually related to certain factors like the size of the CD cavity and the nature of modified groups of $\mathrm{CD}$. The shape, volume, polarity, number and character of substituting groups of guest, as well as reaction medium, temperature and ionic strength, will affect the form and relative strength of these forces [23, 24]

\section{Solubility studies}

The results of solubility studies were given in table 1 . The solubility of LOR/CD complexes was significantly $(\mathrm{P}<0.05)$ higher than that reported for pure LOR which was $1.2 \mathrm{mg} / 100 \mathrm{ml}$ [25]. The solubility of the formulated complexes was entirely affected by the Drug: CD ratio. It was found that the 1:2 ratio achieved the highest amount dissolved regardless to the type of CD used which may be attributed to the high complexation efficiency in 1:2 complex. There was a significant difference in solubility between $1: 2$ and $3: 2$ complexes. However, no significant difference in solubility between 1:1 and 1:2 complexes was observed. The solubility of HPCD complexes was more than that of $\beta C D$ complexes. This is because the solubilizing effect of CD derivatives is in the following order: HPCD $>\beta C D$ [26]. HPCD has higher water solubility and safety compared to other CDs [27] Regarding the effect of the preparation method, statistical analysis of data revealed that there was no significant impact from using either the freeze-drying or physical mixing on the solubility of the prepared complexes $(\mathrm{p}<0.05)$.

Lipophilic compounds like LOR bound non-covalently to the hydrophobic cavity of the CD molecule to form inclusion complexes which in turn altered the aqueous solubility of the drug [28]. Inclusion systems occur when some of the guests have been incorporated in the sandwich structure formed by intermolecular hydrogen bonds between two CD molecules [29] or stay completely out of the cavity [30]. Further evidence of the complex formation was obtained by differential scanning calorimetry, X-ray diffractometry and by FTIR spectroscopy.

Table 1: Formulation codes and solubility of the prepared mixtures

\begin{tabular}{|c|c|c|c|c|c|c|c|c|c|c|c|c|}
\hline $\begin{array}{l}\text { Formulati } \\
\text { on code }\end{array}$ & pm11b & pm12b & $\begin{array}{l}\text { pm32 } \\
\text { b }\end{array}$ & pm11h & pm12h & pm32h & fd11b & fd12b & fd32b & fd11h & fd12h & fd32h \\
\hline $\begin{array}{l}\text { Preparati } \\
\text { on method }\end{array}$ & physical & xing & & & & & freeze-dr & ing & & & & \\
\hline $\begin{array}{l}\text { Polymer } \\
\text { type }\end{array}$ & $\beta C D$ & $\beta C D$ & $\beta C D$ & HPCD & HPCD & HPCD & $\beta C D$ & $\beta C D$ & $\beta C D$ & HPCD & HPCD & HPCD \\
\hline $\begin{array}{l}\text { Ratio } \\
\text { (drug/CD) }\end{array}$ & $1: 1$ & $1: 2$ & $3: 2$ & $1: 1$ & $1: 2$ & $3: 2$ & $1: 1$ & $1: 2$ & $3: 2$ & $1: 1$ & $1: 2$ & $3: 2$ \\
\hline $\begin{array}{l}\text { Solubility } \\
(\mathrm{mg} / 100 \\
\mathrm{ml})^{\mathrm{a}}\end{array}$ & $\begin{array}{l}4.53 \pm 0.2 \\
27\end{array}$ & $\begin{array}{l}5.04 \pm 0.2 \\
52\end{array}$ & $\begin{array}{l}4.19 \pm .2 \\
1\end{array}$ & $\begin{array}{l}4.71 \pm 0.2 \\
35\end{array}$ & $5.58 \pm 0.279$ & $\begin{array}{l}4.16 \pm 0 . \\
208\end{array}$ & $\begin{array}{l}5.14 \pm 0.2 \\
42\end{array}$ & $\begin{array}{l}5.61 \pm 0.2 \\
66\end{array}$ & $\begin{array}{l}4.51 \pm 0.2 \\
11\end{array}$ & $\begin{array}{l}5.62 \pm 0.2 \\
66\end{array}$ & $\begin{array}{l}6.21 \pm 0.2 \\
96\end{array}$ & $\begin{array}{l}4.64 \pm 0.2 \\
17\end{array}$ \\
\hline
\end{tabular}

${ }^{a}$ mean $\pm S D, n=3$, pm11b means 1:1 Lornoxicam: $\beta$-cyclodextrin physical mixture, pm12b means 1:2 Lornoxicam: $\beta$-cyclodextrin physical mixture, pm32b means 3:2 Lornoxicam: $\beta$-cyclodextrin physical mixture, pm11h means 1:1 Lornoxicam: hydroxyl propyl $\beta$-cyclodextrin physical mixture, pm12h means Lornoxicam: hydroxyl propyl $\beta$-cyclodextrin physical mixture, pm32h means 3:2 Lornoxicam: hydroxyl propyl $\beta$-cyclodextrin physical mixture, fd11b means 1:1 Lornoxicam: $\beta$-cyclodextrin freeze-dried mixture, fd12b means 1:2 Lornoxicam: $\beta$-cyclodextrin freeze-dried mixture, fd32b means 3:2 Lornoxicam: $\beta$-cyclodextrin freeze-dried mixture, fd11h means 1:1 Lornoxicam: hydroxyl propyl $\beta$-cyclodextrin freezedried mixture, fd12h means 1:2 Lornoxicam: hydroxyl propyl $\beta$-cyclodextrin freeze-dried mixture, and fd32h means 3:2 Lornoxicam: hydroxyl propyl $\beta$-cyclodextrin freeze-dried mixture.

\section{Differential scanning calorimetry (DSC)}

Thermal analysis is conducted to evaluate the possible physical and chemical changes that might happen in heated samples. DSC thermograms are shown in fig. 1. LOR exhibited two characteristic endothermic peaks at $220{ }^{\circ} \mathrm{C}$ and $260.9^{\circ} \mathrm{C}$ indicating a cubic crystal polymorph form [31]. $\beta C D$ presents broad endothermic peaks at 108
${ }^{\circ} \mathrm{C}$ and $318.5^{\circ} \mathrm{C}$. HPCD presents endothermic peaks at $92.88^{\circ} \mathrm{C}$ and $295.4^{\circ} \mathrm{C}$. The thermal behavior of HPCD exhibited no phenomena in any temperature intervals. In all of the prepared complexes, there is slight dislocation of the peaks indicating the possibility of complex formation. Similar results were observed in complexation between $\beta C D$ and carbamazepine [32]. But in freeze-dried mixtures, the dislocation of peaks is more than that of physical mixtures. Also, the intensity of peaks 
in freeze-dried mixtures is more reduced than in physical mixtures. The decrease in intensity of the peak in the thermogram of the freeze-dried complexes could be attributed to the inclusion of LOR in CD molecule [33]. The change in peaks may be related to a physical interaction between LOR and CD indicating the formation of an amorphous system. In the freeze-dried complex, LOR was dispersed in the amorphous host and altered its crystallisation. Similar results were obtained in complexation between $\beta C D$ and piroxicam [34]. In fig. 1D, 1G, $1 \mathrm{~J}$ and $1 \mathrm{M}$, endothermic peaks were more reduced in HPCD 1:1 complex than $\beta C D$
1:1 complex indicating more inclusion of LOR in HPCD. The intensity of the peaks was more reduced in $1: 2$ complexes than $1: 1$ complexes indicating more effective inclusion as shown in fig. $1 \mathrm{E}, 1 \mathrm{H}, 1 \mathrm{~K}$ and $1 \mathrm{~N}$. Similar results were observed in 1:2 inclusion complex between of $\beta C D$ with iodide ion [35] as well as the complex of hexakis (3-0-acetyl2 , 6-di-0-methyl)- $\alpha$-CD with butyl acetate [28]. The intensity of the peaks in 3:2 complex was not reduced much (fig. 1F, 1I, 1L and 10) indicating less effective inclusion as appeared in the complex of $\beta C D$ with 1,10 phenanthroline [36].
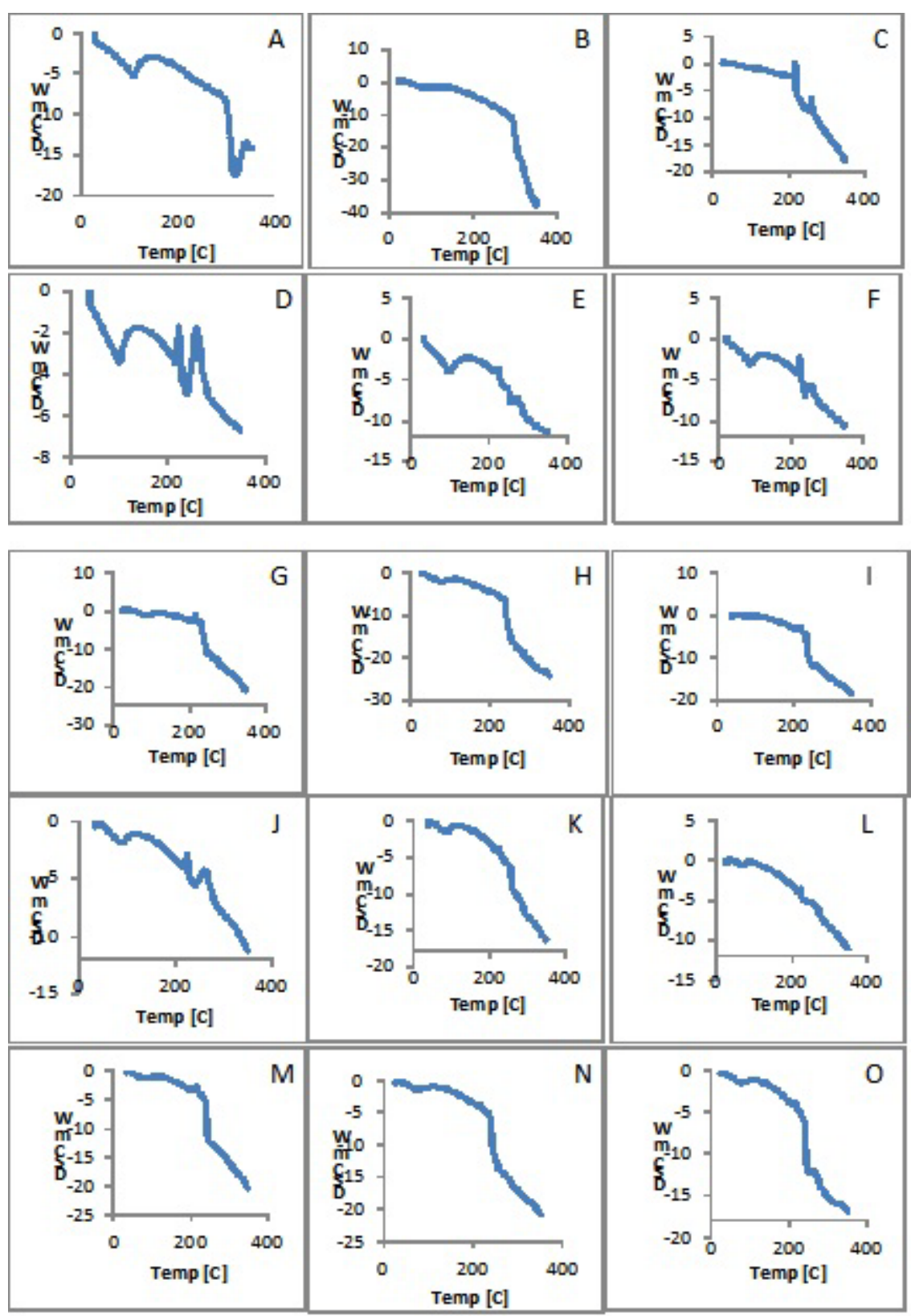

Fig. 1: Showing DSC for of (A) $\beta C D,(B)$ HPCD, (C) LOR, (D) pm11b, (E)) pm12b, (F) pm32b, (G) pm11h, (H) pm12h, (I) pm32h, (J) fd11b, (K) fd12b, (L) fd32b, (M) fd11h, (N) fd12h, (0) fd32h

\section{Scanning electron microscopy (SEM)}

The photomicrographs obtained for the prepared LOR-CD solid complexes were presented in fig. 2 . $\beta C D$ and HPCD revealed rough particles with fissures and irregular surface (fig. $2 \mathrm{H}, 2 \mathrm{I}$ ). In physical mixtures, the particles of LOR and CD were clearly distinguished from each other (fig. 2G, 2J, 2k), this suggests that there is no chemical or physical interaction occurs between them. While in freeze-dried mixtures, there is more interaction between LOR and CD. The particles are amorphous with a smooth shape and reduced size (fig. 2A, 2D, 2F). This explains the higher solubility of the freezedried mixtures than that of physical mixtures [10]. As shown in fig. $2 \mathrm{C}$ and 2D, the particles of HPCD complex were more amorphous than $\beta C D$ complex particles confirming the above results that HPCD forms more soluble complex than $\beta C D$. The effect of LOR to CD ratio on solubility was not clearly observed in the SEM micrographs. 

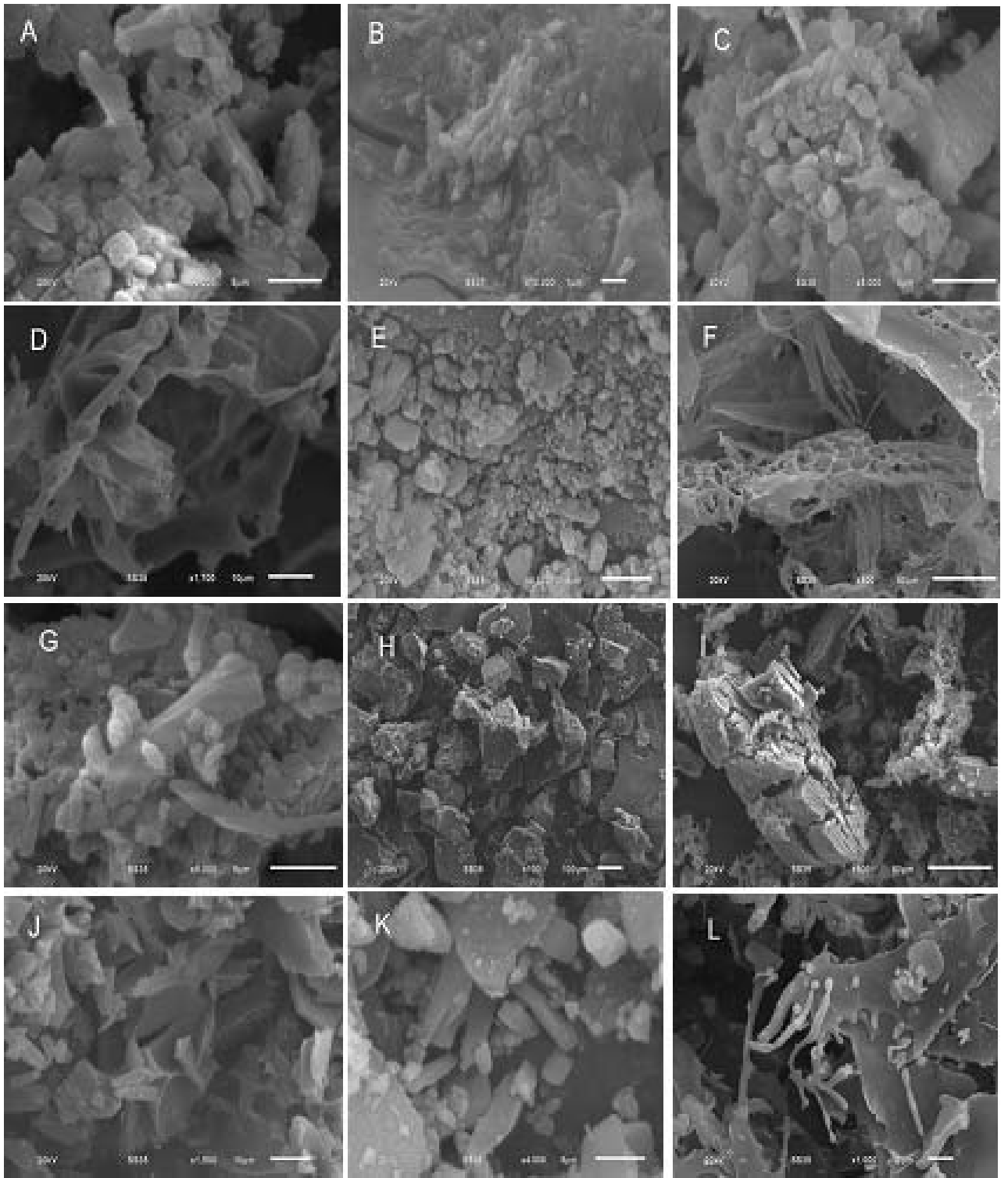

Fig. 2: Showing SEM photomicrographs of (A) fd11b, (B) fd11h, (C) fd12b, (D) fd12h, (E) fd32b, (F) fd32h, (G) pm11b, (H) pm11h, (I) pm12b, (J) pm12h, (K) pm32b, (L) pm32h

\section{X-ray diffraction}

The solid-state form, like as crystalline, polymorphs, solvates or amorphous solids of a drug substance, can have a significant impact on drug's solubility, dissolution rate, stability in a pharmaceutical formulation and bioavailability [37, 38]. A crystal has an ordered arrangement of molecules and atoms, maintained in contact through non-covalent interactions while amorphous solids are characterised by a random state.

Although the amorphous solids are often susceptible to changes during storage, the amorphous form of a drug is generally more soluble, due to free energies involved in the dissolution process. This characteristic of solubility is a useful property for low aqueous solubility drugs [39]. Fig. 3 represents the reflectograms of the mixtures. Fig. 3A shows that $\beta C D$ in crystal form. Fig. 3B shows that HPCD in amorphous form. Fig. 3 C shows that LOR in crystal form. In physical and freeze-dried mixtures, it was observed that the peaks size was reduced. This indicated the formation of amorphous solid as in fig. 3D, 3E. Also, it was noticed that HPCD form more amorphous mixtures than that of $\beta C D$. It was observed in fig. 3E, 3G and 3 I that $1: 2$ complexes were more amorphous than $1: 1$ complex and 3:2 complex as the peaks size were highly reduced indicating high solubility of $1: 2$ complex and confirming the above results. 3:2 inclusion complexes were obtained when two LOR molecules were included into cavities of two CD molecules while the third one appears in the interstitial region formed by the wider rims of the cavities of two CD molecules. Similar examples were found in the complexes of $\beta C D$ with 1-propanol and 4-iodophenol [40]. In fig. 3E and $3 \mathrm{~K}$, it was observed that freeze-drying method from slightly more amorphous crystals than physical mixing method [26, 33].

\section{Nuclear magnetic resonance spectroscopy}

Fig. 4 presented ${ }^{1} \mathrm{H}$ NMR data of the complexes prepared by the physical mixture and freeze-drying. The results suggested that LOR is externally associated with $\mathrm{CD}$ as there is an interaction between $\mathrm{H}_{4}$ of HPCD (3.31-3.37 ppm) and hydrogen's of the aromatic ring of LOR (7.56-7.72 ppm). These data suggest that at least part of the drug molecule interacts with the CD cavity and is encapsulated [25].

Similar effects have been previously described in the interaction between ABPP and b-CD [41]. The association complexes formed increase the aqueous solubility of LOR 

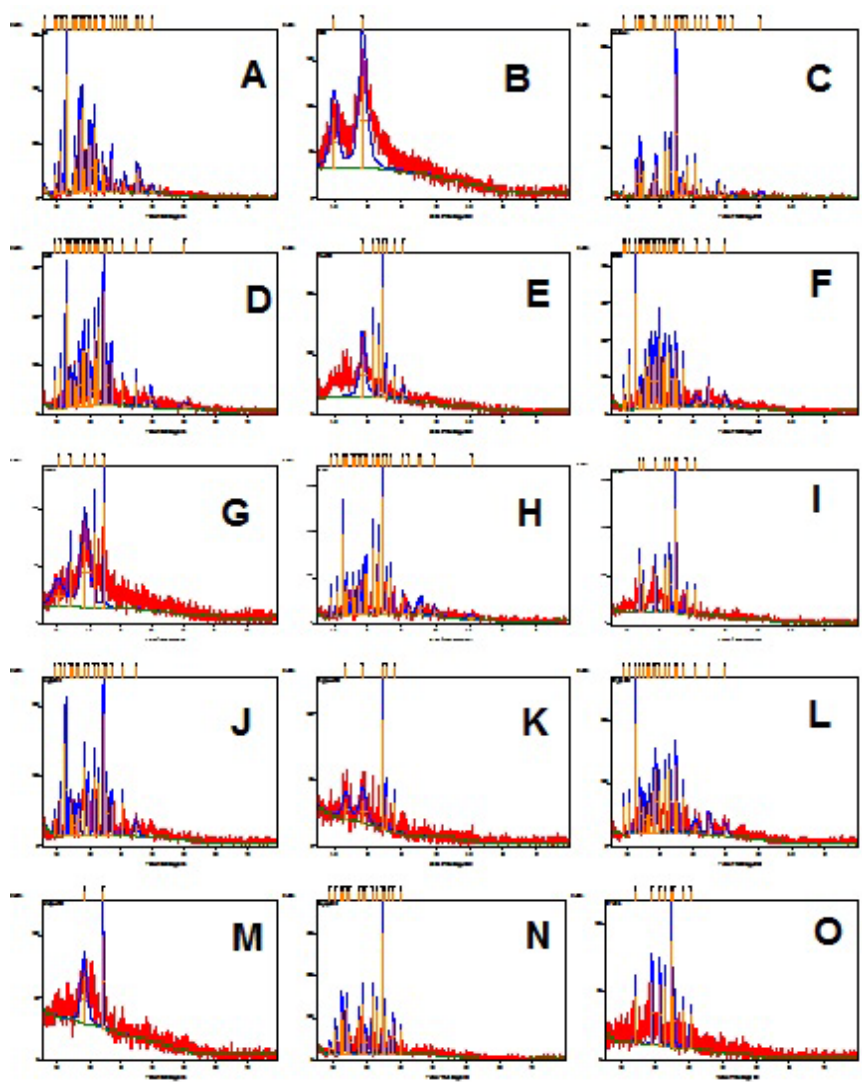

Fig. 3: Showing the representative X-ray diffraction patterns for of (A) $\beta C D,(B)$ HPCD, (C) LOR, (D) pm11b, (E) pm11h, (F) pm12b, (G) pm12h, (H) pm32b, (I) pm32h, (J) fd11b, (K) fd11h, (L) fd12b, (M) fd12h, (N) fd32b, (0) fd32h

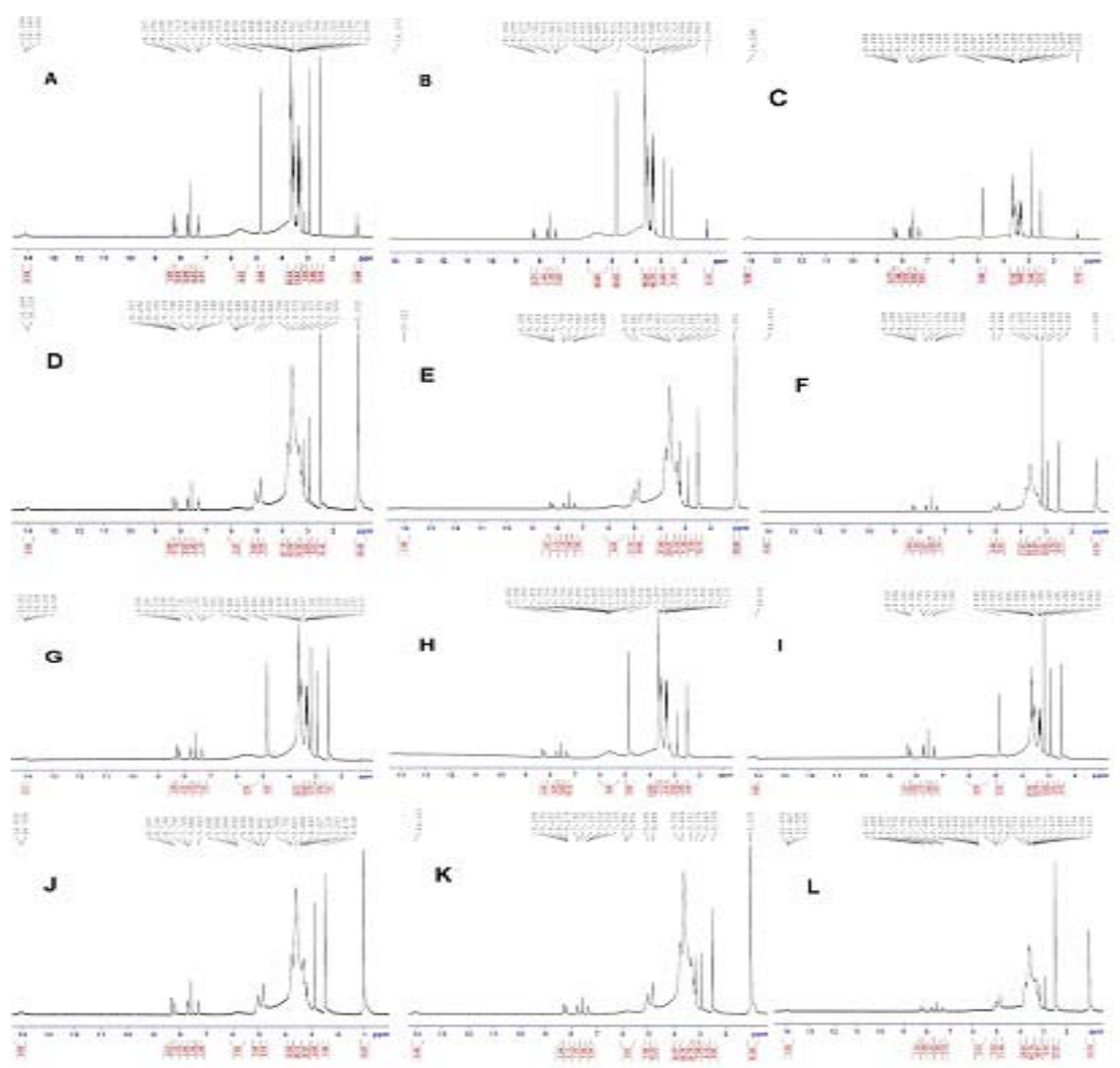

Fig. 4: (A) pm11b, (B) pm12b, (C) pm32b, (D) pm11h, (E) pm12h, (F) pm32h, (G) fd11b, (H) fd12b, (I) fd32b, (J) fd11h, (K) fd12h, (L) fd32h 


\section{Fourier transform infrared (FT-IR)}

FT-IR spectra are presented in fig. 5. LOR spectra showed the band at $3412 \mathrm{~cm}^{-1}$. The FT-IR spectrum of $\beta C D$ presents a large band and a peak in the region of $3500-3000 \mathrm{~cm}^{-1}$ that belongs to stretching vibrations of primary $\mathrm{OH}$ [31]. Absorption bands of stretching vibrations of $\mathrm{C}-\mathrm{O}, \mathrm{C}-\mathrm{C}$, and deformation vibrations of $\mathrm{O}-\mathrm{H}$ bonds from primary and secondary alcohols of $\beta C D$ occur in the range 1600-1000 $\mathrm{cm}-1$ [42]. The FT-IR spectrum of HPCD presented a profile without distinctly high peaks. The physical mixture FT-IR spectrum showed approximately the superposition of the drug and HPCD, while the inclusion complex showed spectra with broader and shifted bands, suggesting the formation of hydrogen bonds between the carbonyl group of LOR and the hydroxyl group of the host cavity [33].

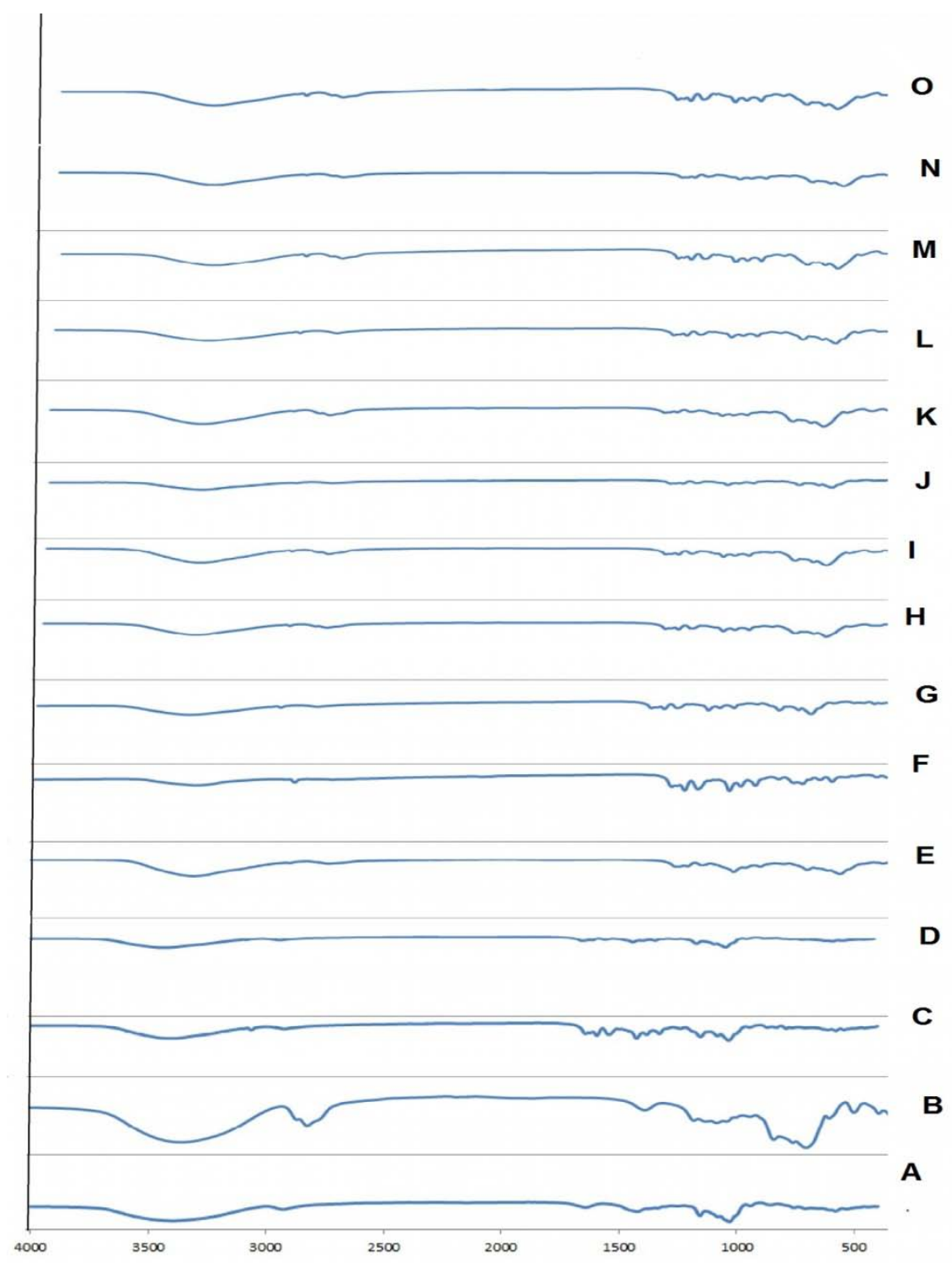

Fig. 5: FT-IR spectra of (A) $\beta C D,(B)$ HPCD, (C) LOR, (D) pm11b, (E) pm12b, (F) pm32b, (G) pm11h, (H) pm12h, (I) pm32h, (J) fd11b, (K) fd12b, (L) fd32b, (M) fd11h, (N) fd12h, (O) fd32h

\section{CONCLUSION}

In this work, LOR solubility was enhanced through its complexation with $\beta C D$ and HPCD by the physical mixture and freeze-drying techniques. The complexes obtained by freeze-drying presented higher solubility compared to those containing the simple physical mixture. It was noticed that the complexes were transformed to amorphous forms. Finally, HPCD and freeze-drying technique have higher but not significantly different solubilizing effect than $\beta C D$ and physical mixture technique respectively. It may be statistically different on a large scale. The formation of such complexes could be regarded as a promising strategy for improving the bioavailability of LOR.

\section{CONFLICTS OF INTERESTS}

The author has no declaration of interest.

\section{REFERENCES}

1. Ingle P, Patil PH, Lathi V. Study of rational prescribing and dispensing of prescriptions with non-steroidal antiinflammatory drugs in the orthopedic outpatient department. Asian J Pharm Clin Res 2015;8:278-81.

2. Banerjee R, Chakraborty H, Sarkar M. Photophysical studies of oxicam group of NSAIDs: piroxicam, meloxicam and tenoxicam. Spectrochim Acta Part A 2003;59:1213-22.

3. Sarangi MK, Padhi S. Colon targeted drug delivery system an approach for treating colonic ailments. J Crit Rev 2015;2:12-8.

4. Song L, Bai L, Xu X, He J, Pan S. Inclusion complexation, encapsulation interaction and inclusion number in cyclodextrin chemistry. Coord Chem Rev 2009;253:1276-84.

5. Yatsu F, Koester L, Lula I, Passos J, Sinisterra R, Bassani V. Multiple complexations of cyclodextrin with soy isoflavones 
present in an enriched fraction. Carbohydr Polym 2013; 98:726-35.

6. Loftsson T, Brewster M. Pharmaceutical applications of cyclodextrins. 1. Drug solubilization and stabilisation. J Pharm Sci 1996;85:1017-25.

7. Rajewski RA, Stella VJ. Pharmaceutical applications of cyclodextrins 2. In vivo drug delivery. J Pharm Sci 1996;85:1142-69.

8. ME Dalmora, SL Dalmora, G Oliveira. Inclusion complex of piroxicam and B-cyclodextrin and incorporation in the cationic microemulsion. In vitro drug release and in vivo topical antiinflammatory effect. Int J Pharm 2001;222:45-55.

9. T Loftsson, AM Sigurdardottir, H Olafsson. Improved acitretin delivery through hairless mouse skin by cyclodextrin complexation. Int J Pharm 1995;115:255-8.

10. Riekes M, Tagliari M, Granada A, Kuminek G, Silva M, Stulzer H. Enhanced solubility and dissolution rate of amiodarone by complexation with $\beta$-cyclodextrin through different methods. Mater Sci Eng C 2010;30:1008-13.

11. Rossel C, Sepúlveda Carreño J, Rodríguez-Baeza M, Alderete J. Inclusion complex of the antiviral drug acyclovir with cyclodextrin in aqueous solution and in the solid phase. Química Nova 2000;23:749-52.

12. Zerrouk N, Corti G, Ancillotti S, Maestrelli F, Cirri M, Mura P. Influence of cyclodextrins and chitosan, separately or in combination, on glyburide solubility and permeability. Eur J Pharm Biopharm 2006;62:241-6.

13. Ventura C, Tommasini S, Falcone A. Influence of modified cyclodextrins on solubility and percutaneous absorption of celecoxib through human skin. Int J Pharm 2006;314:37-45

14. Archontaki H, Vertzoni M, Athanassiou-Malaki M. Study on the inclusion complexes of bromazepam with $\beta$-and $\beta$-hydroxypropylcyclodextrins. J Pharm Biomed Anal 2002;28:761-9.

15. Lu Z, Cheng B, Hu Y, Zhang Y, Zou G. Complexation of resveratrol with cyclodextrins: solubility and antioxidant activity. Food Chem 2009;113:17-20.

16. Ali MF. Topical delivery and photodynamic evaluation of a multivesicular liposomal Rose Bengal. Lasers Med Sci 2011; 26:267-75.

17. Kim ED, El-rashidy R, McVary KT. Papaverine topical gel for the treatment of erectile dysfunction. J Urol 1995;153:361-5.

18. Szejtli J. Introduction and a general overview of cyclodextrin chemistry. Chem Rev 1998;98:1743-54.

19. Hapiot F, Tilloy S, Monflier E. Cyclodextrins as supramolecular hosts for organometallic complexes. Chem Rev 2006;106:767-81.

20. Harata K. X-ray structure of hexakis (2, 3, 6-tri-0-acetyl)ALPHA.-cyclodextrin. Chem Lett 1998;7:589-90.

21. Li S Purdy W. Cyclodextrins and their applications in analytical chemistry. Chem Rev 1992;92:1457-70.

22. Mohanty J, Bhasikuttan A, Nau W, Pal H. Host guest complexation of neutral red with macrocyclic host molecules: contrasting $\mathrm{p} \mathrm{K}$ shifts and binding affinities for cucurbit [7] uril and $\beta$-cyclodextrin. J Phys Chem B 2006;110:5132-8.

23. Rekharsky M, Inoue Y. Complexation thermodynamics of cyclodextrins. Chem Rev 1998;98:1875-918.

24. Al-Omari M, Zughul M, Davies J, Badwan A. Thermodynamic enthalpy-entropy compensation effects observed in the complexation of basic drug substrates with $\beta$-cyclodextrin. J Inclusion Phenom Macrocyclic Chem 2007;57:379-84.

25. SZ Chemate, KPR Chowdary. A factorial study on enhancement of solubility and dissolution rate of lornoxicam employing $\beta$ cyclodextrin and surfactants. Int J Pharm Res Dev 2012;4:350-6.
26. Echezarreta-López M, Torres-Labandeira J, Castiñeiras-Seijo L, Santana-Penín L, Vila-Jato J. Complexation of the interferon inducer, bropirimine, with hydroxypropyl- $\beta$-cyclodextrin. Eur J Pharm Sci 2000;9:381-6.

27. Prabhakaran R, Janakiraman K, Harindran J. Formulation and evaluation of taste masked oral suspension of cefuroxime axetil using hydroxypropyl-beta-cyclodextrin. Asian J Pharm Clin Res 2016;9:90-2.

28. Nagase $\mathrm{Y}$, Hirata $\mathrm{M}$, Wada $\mathrm{K}$, Arima H, Hirayama $\mathrm{F}$, Irie $\mathrm{T}$, et al. Improvement of some pharmaceutical properties of DY-9760e by sulfobutyl ether $\beta$-cyclodextrin. Int J Pharm 2001;229:163-72.

29. Fan Z, Diao C, Yu M, Jing Z, Chen X, Deng Q. An investigation of the inclusion complex of $\beta$-Cyclodextrin with 8-nitro-quinoline in the solid state. Supramol Chem 2006;18:7-11.

30. Harata K, Song L, Morii H. X-ray structure of a 1:2 complex of hexakis (3-0-acetyl-2,6-di-0-methyl)- $\alpha$-cyclodextrin with butyl acetate. J Supramol Chem 2000;11:217-24.

31. Vrečer F, Vrbinc M, Meden A. Characterization of piroxicam crystal modifications. Int J Pharm 2003;256:3-15.

32. Koester L. Influence of $\beta$-cyclodextrin complexation on carbamazepine release from hydroxypropyl methylcellulose matrix tablets. Eur J Pharm Biopharm 2003;55:85-91.

33. Jug, M, Bećirević-Laćan M. Influence of hydroxypropyl- $\beta$ cyclodextrincomplexation on piroxicam release from buccoadhesive tablets. Eur J Pharm Sci 2004;21:251-60.

34. Redenti E, Peveri T, Zanol M, Ventura P, Gnappi G, Montenero A. A study on the differentiation between amorphous piroxicam: $\beta$-cyclodextrin complex and a mixture of the two amorphous components. Int J Pharm 1996;129:289-94.

35. Lindner K, Saenger W. Crystal and molecular structures of cyclomaltoheptaose inclusion complexes with $\mathrm{HI}$ and with methanol. Carbohydr Res 1982;107:7-16.

36. Liu Y, Chen G, Zhang H, Song H, Ding F. Interaction between $\beta$ cyclodextrin and 1,10-phenanthroline: uncommon 2:3 inclusion complex in the solid state. Carbohydr Res 2004;339:1649-54.

37. Markovich R, Anderson Evans C, Coscolluela C, Zibas S, Rosen J. Spectroscopic identification of an amorphous-to-crystalline drug transition in a solid dispersion SCH 48461 capsule formulation. J Pharm Biomed Anal 1997;16:661-73.

38. Ford JL. The current status of solid dispersions. Pharm Acta Helv 1986;61:69-88.

39. Stulzer H, Tagliari M, Parize A, Silva M, Laranjeira M. Evaluation of cross-linked chitosan microparticles containing acyclovir obtained by spray-drying. Mater Sci Eng C 2009;29:387-92.

40. Stezowski J, Jogun K, Eckle E, Bartels K. Dimeric $\beta$-cyclodextrin complexes may mimic membrane diffusion transport. Nature 1978;274:617-9.

41. Ahmed S, Naggi A, Guerrini M, Focher B. Inclusion complexes of bropirimine with $\beta$-cyclodextrin in solution and in the solid state. Int J Pharm 1991;77:247-54.

42. Silverstein R, Webster F, Kiemle D. Spectrometric identification of organic compounds. New York: Wiley; 2004.

\section{How to cite this article}

- $\quad$ Shahira F EL-Menshawe, Essam Eissa, Adel A Ali, Ahmed A Abderhman. Enhancement of lornoxicam solubility by inclusion complexation with cyclodextrin: preparation and characterization. Int J Pharm Pharm Sci 2017;9(1):132-138. 